ment of anatomy, surgery, and physic." Upon this being declined, he commenced building the Hunterian School in Great Windmill-street, comprising a mansion, museum, theatre, and anatomical department. He removed into the house in 1768, resigning his house in Jermyn-street to John Hunter, where he lived until he removed to Leicester-square in 1783. Most accounts give the date as 1770 ; but the lists of the College of Physicians show that his address in 1767 was Jermyn-street, and Great Windmill-street in 1768. In 1771 he was joined by Cruickshank, who lectured until the day of his death in 1800. On March 15th, 1783, he commenced a course of lectures on Surgery, but was removed from the theatre in an insensible state, to die on the 30th of the same month. In 1784 his nephew, Mathew Baillie, joined Cruickshank in lecturing, and continued to do so until 1799. In 1785 James Wilson, a pupil of William and John Hunter, commenced as demonstrator to Baillie, and when he quitted the school he became joint lecturer with Cruickshank, and continued teaching until his death in 1821, which was as sudden as his predecessors', Hunter and Cruickshank. In 1807 Wilson purchased the freehold of the premises in Great Windmill-street, and inhabited the house, as Hunter and Baillie had previously done. $\mathrm{He}$ subsequently sold the property, reserving the school part of the premises on a lease. When Honoratus Leigh Thomas began to teach in Great Windmill-street I am not certain. Brodie found him there in 1802, and says in his Autobiography :- "He delivered only a few anatomical lectures. He was not fond of his vocation as a teacher, and was led to play truant a good deal." In 1805 he resigned, when Brodie commenced to teach in Great Windmill-street, which he continued to do until 1812, when Wilson proposed that he should take the school off his hands. This offer he declined, not possessing the funds required for the transfer. Thus ended his career as a teacher of anatomy. In 1808 he had commenced lecturing on surgery, and on parting from Wilson he took a house in Great Windmill-street, where he built a theatre and museum; these lectures he continued until 1830, when the school removed to St. George's Hospital. On Brodie's retirement from the school in 1812 Charles Bell joined Wilson. He had commenced lecturing in London in 1806. In one of those most interesting letters published in 1870which anybody wishing to have an insight of medical society at the commencement of the present century should read-he says : "I resolved to remain in London, and took a large ruinous house in Leicester-square, previously inhabited by Speaker Onslow. When I got into the house, the first night I slept in it, I had put ont the candle, and leaping into bed, the floor gave way under my foot, and I found that I had displaced the board. On examining this in the morning I discovered a tube under the loose board; it was the house where the 'invisible girl ' exhibited!" In a letter, October 7 th, 1812 , he says, "I gave my first lecture yesterday in Great Windmill-street. I gave an hour and a half to a full class; there were from eighty to a hundred, not gathered for the occasion, but pupils of the class." His brother-in-law, John Shaw, assisted him in his lectures and dissections until his death, which took place in 1827 . In one of his letters at this time he says: "I have lost my dear and best friend, Juhn Shaw. There is such a blank, I have not an idea left." In 1828 Bell opened the Medical School at University College, then called London University. On the institution of this school, Sir Benjamin Brodie was solicited by the Council to undertake the duties of either professor of anatomy or surgery, with any assistants he might wish to have. In 1826 Herbert Mayo and Casar Hawkins purchased Bell's interest in the school, he continuing to lecture in the session 1826-27, and they carried on the school until October, 1830, when Cæsar Hawkins left for the opening of St. George's Hospital School, and Mayo in 1831 for King's College. In the winter session of 1830.31 Mr. Thomas Tatum gave the anatomical demonstrations. Subsequently, Mr. Gregory Smith and Mr. Bushell delivered lectures. Mr. Smith afterwards removed to the school in Iittle Windmill-street, where Mr. Prescott Hewett joined him in October, 1836, as demonstrator previous to his being house-surgeon at St. George's Hospital in 1838.

I venture to add some criticisms on those I have mentioned as teachers. Baillie said of William Hunter: "He excelled very much any lecturer whom I have ever heard in the clearness of his arrangements, the aptness of his illustrations, and the elegance of his diction; he was perhaps the best teacher of anatomy that ever lived." Brodie, born the year William Hunter died, says in his Hunterian Oration, delivered in 1837 : "Hewson partook in no small degree of his master's zeal and industry, and his works show how much may be accomplished by means of these qualities when in. fused into a mind of moderate dimensions. Cruickshank, over-sensitive and hypochondriacal as he was from disease, was much superior to Hewson; his physiological papers in the Philosophical Transactions and his treatise on the absorbent vessels exhibit a combination of genius and learn. ing, and justify us in assigning him a very high place in the scale of men of genius." And in his Autobiography he says of Wilson: "He had a most profound knowledge of his subject, and his demonstrations were very far superior to those of any other anatomist of that day "-and I may, I believe, add to those of any one since.

In writing this sketch of a school I have been struck with an interesting intellectual lineage. A sister of William and John Hunter was the mother of Mathew Baillie and his gifted sister, the well-known authoress. Baillie married the daughter of the celebrated Dr. Denman, the father of the first Lord Denman, distinguished as a great lawyer. Dr. Denman married the aunt of Sir Benjamin Brodie. The second Sir B. Brodie, by his writings in science, gave evidence of his claim to be ranked as a distinguished professor of chemistry. Dr. Baillie's son, Mr. William Hunter Baillie, is one of the present trustees of the Hunterian Museum at the College of Surgeons.

Savile-row.

\section{OSTEOTOMY FOR GENU VALGUM.}

BY WILLIAM MACEWEN, M.D. GLASG., SURGEON AND LECTURER ON SURGERY, ROYAL INFIRMARY, AND SURGEON TO THE CHILDREN'S HOSPITAL, GLASGOW.

Osteotomy, as a means of cure of genu valgum, has been before the profession now for about seven years, and during the last three or four it has been very exten. sively adopted by surgeons over the civilised world. The present is therefore a fitting time for eliciting an ex. pression of opinion concerning it. From the manner in which the subject has been framed, I apprehend that we are not to discuss the various methods of treatment of genu valgum, but that we are to confine our attention to osteotomy for that disease. In the limited time at our disposal it is necessary that we confine our attention to a few points only I have considered that the two following could be discussed with advantage :-

1. The variou s methods of performing osteotomy for genu valgum and their comparative qualities.

2. The results of these operations.

As to the first point, we have to consider whether the intra- or the extra-articular method ought to be adopted, whether the femur or the tibia ought to be selected for the operation. It is presumed that all of the members are suff. ciently acquainted with the descriptions of Ogston's (and its various modifications), Billroth's, Schede's, Chiene's, and Macewen's operations to render it unnecessary to say any. thing on these points. It would be out of place in me to say anything as to the comparative qualities of these opera. tions, considering my close connexion with the last one mentioned. I have the more reason for doing this as I know that the gentlemen whose names are most closely identified with the various operations are present. Regarding the second question, I have gathered statistics which will belp the members in forming a conclusion on the subject.

A schedule was drawn out, asking for statistics concerning osteotomy for genu valgum, and a copy was addressed to every hospital surgeon in Britain. Replies have been received from about forty-five surgeons, but only thirty. seven of these have been able to answer the questions sufficiently fully to permit of them being of value. The statistics received have been formed into a table, which is here presented to the members of the International Medical Con. gress. The table must not be understood to be a complete one, inasmuch as many surgeons have not been able to reply, which it is hoped they will yet do. With regard to con. tinental and American surgeons, I trust to be able to arrange a similar scheme by which they may be inclined to favour

1 A paper read as introduction to a discussion on Osteotomy for Genu Valgum, International Medical Congress, Copenhagen, 1884. 
me with their results, so as to obtain as wide a basis for deduction as possible. The table as it stands is made up of statisties furnished by thirty-seven surgeons. They have operated on 1118 limbs. In some instances only have the number of patients, as well as the number of limbs, been given. The ages of the persons operated on extend from three to thirty-nine years. The operations which have been chosen by those thirty-seven surgeons are as follows :-

Three surgeons have performed Ogston's exclusively; eight surgeons have performed sometimes Ogston's, sometimes another operation. Eleven surgeons in all have used Ogston's operation ; these eleven surgeons have operated on 525 limbs, one gentleman alone having performed 370 .

Chiene's method has been used exclusively by one surgeon, Professor Chiene himself, One surgeon has twice performed Chiene's along with another method of osteotomy. Two surgeons have thus performed Chiene's operation; these two have performed operations on fifteen limbs.

No one has operated by Schede's method exclusively. Two surgeons have performed oscasionally Schede's operation; these two surgeons have operated by Schede's method on five limbs.

Twenty-two surgeons have used Macewen's method exclusively. Eleven surgeons have used Macewen's method occasionally, giving a total of thirty-three surgeons out of thirtyseven who have used Macewen's method; these thirty-three surgeons have operated on 580 limbs.

The next question referred to accidents during the operations, Hæmorrhage is mentioned in two of Macewen's, in thirteen of Ogston's, and in one of Chiene's. The knife was broken off in the joint in one of Ogston's. As to the conduct of the operation, thirty-four of the surgeons used spray and other Listerian precautions, while three conducted the operation by the open method.

The progress under treatment shows that thirty-two cases of Macewen's operation afterwards suppurated, eight cases of Ogston's, and one of Chiene's-that is, forty-one in all have suppurated. Of fatalities there are five cases in all after Macewen's operation. One from blood poisoning (this though stated to be Macewen's operation was not in reality such), one from septicænia, one from phthisis, one from congestion of the lungs, and one from scarlet fever. In the last three the operation is not credited with the result. Of recoveries there have been 1113 out of $1118 \mathrm{limbs}$. The results as to utility of limbs show that anchylosis has taken place in two of Macewen's operations, in four of Ogston's (one with dislocation of the patella), and in one of Caiene's. In two of Ogston's bow legs resulted after the operation. All the others were good.

As to relapses after the operation, Macewen's operation has been followed by four such, mostly occurring in young children (one stated to have recovered after using supports for a short time is not counted). One gentleman who has performed both Ogston's and Macewen's has had three returns to the deformed condition. In one of Chiene's there was a return, but in this case the patient had led an irregular life. In one of Chiene's, amputation had to be resorted to about a year after he had performed his operation. The amputation was rendered necessary by the onset of gelatinous degeneration of the synovial membrane. The average duration of treatment has been from one to three months. Mr. Chiene, however, states that he only keeps his patients in the wards for twenty-two days after the operation. Regarding the answer to this question, it is evident that considerable difference of opinion exists as to the meaning of it. Some give the number of days necessary for the patient to remain in bed, while others give the time necessary to fit him for resuming his work.

Statistics of my own Operations - Up to July 31st of this year I have operated on 804 limbs belunging to 490 patients, and on these have performed 820 osteotomies for genu valgum. The ages have been from seven to forty-six years; the great majority being adolescents. The operation was never uadertaken unless after the stage of ramollissement had passed. The supra-condyloid method has been performed alone in 810 instances; in five it was assisted by S shede's operation on the tibia, while in the remaining five molifications of the supra-condyloid method were performed (in the earlier days of my experience) When operating for genu valgum by the supra-condyloid method, the an atomical lines formerly laid d iwn by me have been strictly adhered to, and I have never had occasion to apply a ligature. As a rule there have only been a few drops of blood, sufficient to leave a slight stain on the sponge. The operations have been conducted throughout under the spray, and with strict Listerian precautions.

In eight cases suppuration took place; in six the cause was pressure or some extra force applied, under accidental circumstances. In one it was due to diphtheria of wounds. During the last three years no suppuration ensued after any osteotomy for genu valgum.

Mortality after Supra condyloid Method.-Since the last report two patients, who had been operated on for genu valgum, have died. Both were weak adnlts with marked deformities. The first was aged twenty-four years. He was operated on for aggravated bow-leg and knock-knee. He had a history of hæmoptysis, and the apices of his lungs were dull. From what could be ascertained at the time, as well as from the information supplied by his medical attendant, there were no recent advances of the disease. It was evident that the degree of deformity of his limbs was such that his health was necessarily kept below par by want of exercise. Unless the condition of his limbs was rectified, it was doubtful whether his strength would improve, and it was certain that he could not lead a useful life. So keenly did he feel this that he urged the operation. For the first week after the operation he progressed well. There was no untoward symptom. At the end of that period the temperature began to show a rise in the afternoons. He had a slight cough, accompanied by a considerable degree of aphonia. He had profuse night sweats. The upper portions of his lungs were affected with coarse crepitant râles, except at the very apices, which were dull. On the ninth day after operation there was a thin liquid discharge of pus found in the wound on the bow leg, which continued. His condition gradually became worse; hæmoptysis came on in a severe form, and he died one month and two days after the operation. The postmortem showed that the wound on the bow-leg was not healed. The genu valgum wound was healed, though the union of the bone was weak. The upper lobes of the lung were filled with tubercle; at the apices it was of old standing, having undergone degeneration, while lower there was a tresh deposition of miliary tubercle, with ulceration at parts. The bases were free.

The other case was also that of a weak adult, who had marked genu valgum, preventing him from working or from walking other than very short distances. On the twelfth day after the operation his temperature rose, and on the thirteenth it had reached $102^{\prime} 6^{\circ}$. His limbs were examined, the wounds found healthy, and there was nothing in their appearance to account for the increased temperature. On the fourteenth day it was $103^{\circ}$, and still the cause was not discovered. On the fifteenth a stain was seen on the sheet, and on examination it was found to have proceeded from a sore over the sacrum, of which he had never complained, and stated that he had not been aware of its presence. This sore at first seemed superficial and was covered with a greyish membrane, which on removal left rather a deep raw inflamed surface. Next day it was seen that the area of the sore had considerably increased, and that another layer of greyish membrane implicating the tiesues had formed over its surface. The temperature was now $104^{\circ}$ to $105^{\circ}$. On the seventeenth day he complained for the tirst time of pain in his limbs. The wounds were therefore again inspected, when both were seen to be covered with a greyish false membrane, similar to that which covered the bedsore. There was at this time very little discharge, and the little that was present was serous. This membrane was deeply seated, involving the superficial layers, and penetrated into the interior of the wounds. It was removed but at the next dressing the sores had greatly enlarged, and were again covered by thick false membrane, while the discharge of thin matter-pus and bloody serum-was profuse. It was evident that we had to deal with a case of diphtheria of wounds, showing itself, first, in the sore over the sacrum, rapidly affec'ing the constitution, and through it the wounds on the limbs. Notwithstanding vigorous measures at destruction of the membrane by external means and internal remedies the sores increased with great rapıdity. The greyish membrane on removal exposed a bleediog, raw, inflamed surface. The mucous membranes later became involved, and at the same time he had profuse diarrhoea, with shreds of membrane in the stools. The patient died thirty-two days after the operation and twenty after the onset of the illness. The post-mortem, besides showing the diphtberitic membrane on the sores, revealed its presence in the alimentary canal, the fauces, cesophagus, and rectum. The intestines were much congested. Tue liver was five pounds 
and a half in weight and was two-thirds fatty. The ward drainage was at this time in a bad condition. Several patients who had been operated on for other affections were attacked. Enteric fever became epidemic, nurses and patients being struck down with it. As soon as the drainage was put in order it disappeared. Adding these two deaths to the three formerly reported, there bave been in all five persons who died after the operation for genu valgurn was performed on them; and in none of these was death due to the operation. The only one which admits of doubt is that one in which diphtheria commenced in the sore over the sacrum, and quickly showed constitutional manifestations.

It may be interesting to note that up to Julv 31 st, 1884, I have osteotomised 1267 limbs belonging to 704 patients, and have performed on these 1800 osteotomies; all for deformities of the lower limbs. The deaths from all causes after these operations are : one from pneumonia (contracted on the eve of operation), one from tubercle of the lungs, one from diphtheria of the respiratory passages, one from diphtheria of bedsore and wounds, and one from enteric fever epidemic at the time in the wards (the two last-mentioned deatbs occurred about the same time). The first five were for genu valgum, the last one for genu varum.

Results as to Utility of Limbs.-In all cases there has been improvement in the form, strength, and utility of the limbs of those who have been operated on for genu valgum. Where the knock-knee has been present without complications from other rachitic curves the limbs have been rendered quite straight

The advantages of the operation and the results may be summarised as follows:-A deformity of a very grave kind has been removed; the height of the patient has been increased, often by several inches; the patients have been able to walk easier, much better, and a great deal further than they could prior to the operation. As a consequence they improved in health and strength, and in many instances they have been enabled to occupy situations from which they had previously been debarred. It would be out of place to give cases in detail, especially as they are numbered by hundreds, but by way of illustration the following may be quoted :-

1. A lad eighteen years of age was affected with genu valgum to such an extent that a horizontal line drawn from the internal malleoli measured eighteen inches, while a vertical line running from the horizontal one to the apex of the knees measured fifteen inches. He could neither walk nor stand for more than five minutes at a time, and was totally unfitted for work. After supra-condyloid osteotomy his limbs were straight; he could walk and leap with ease, the movements of the knee-joints being perfect. He was several inches higher than he was prior to the operation. A year afterwards he several times walked eighteen miles at a stretch without fatigue. $\mathrm{He}$ is now engaged as a mechanical engineer, in regular employment, and walks six miles daily in going to and coming from his work. This patient has now been operated on six years. There has never been any weakness of his legs since the operation. He has grown considerably during that time both in height and breadth, and he is a great deal stronger than he was ever likely to be had the operation not been performed.

2. A man twenty-five years of age, affected with double genu valgum (fifteen inches between the malleoli), had to give up his employment some time previous to his admission into my ward on account of his inability to walk to and from his work and difficulty of standing. After supra-condyloid osteotomy his limbs were straight; his knees were freely movable, his stature increased, and he was capable of doing his work with ease. A year afterwards he walked in four consecutive days over 100 miles without fatigue. This man has now been operated on about five years; he is now quite well, and has changed his occupation to that of a traveller for a publishing firm.

3. A third patient, affected with marked genu valgum, could scarcely walk with the help of crutches from his own door to the shop at which he wrought, situated thirty yards distant There he had a sedentary occupation. After operation, besides having straight limbs which were freely movable, his height was increased, and he was able to walk without any support. He changed his residence, walking then daily four miles to his work. At one time he walked ten miles at a stretch without fatigue. He has also been operated on five years, and has had no weakness since.

These are ordinary examples of the results of the supracondyloid operation for genu valgum. In a former paper I have answered the question as to whether the femora grow after supra-condyloid osteotomy. There is abundant proof that the operation does not interfere with the growth of the bone. Mauy patients, from eight to fifteen years of age, have heen operated on, and have now grown considerably, and the femora have grown in proportion with the rest of the body. As an example, one boy aged eight years, affected with genu valgum, measured $4 \mathrm{ft}$. in height; after supra. condyloid osteotomy he measured $4 \mathrm{ft}$. $3 \mathrm{in}$.; four years later he was measured, and found to be $4 \mathrm{ft}$. $10 \mathrm{in}$, the femora having proportionately increased.

Relapses to the acformed Condition. - As to relapses to the deformed condition after osteotomy, I have seen in two cases in which osteotomy was performed for anterior curves of the tibia in young children, who were afterwards the subjects of severe illnesses, that the curve recurred; but in genu valgum, after supra-condyloid osteotomy performed by me I have only once seen a case which showed a return, and that to a very slight extent. It occurred in a boy who had a standing occupation and was poorly fed. Four years afterwards he returned with a slight degree of knock-knee ( 4 in. between the malleoli, while the knees measured 12 in. from the malleoli).

Average Duration of Treatment - The average duration of treatment is six weeks in the splints, and two in the wards after that, while learning to walk. The patients are then advised to go to the convalescent home for two weeks, Three months are ample to enable them to be fitted for walking about and to permit them to engage in their occu. pations again. I have never tried to find the very earliest limit which was necessary to enable the patient to get up and walk about, but rather tried to gain a point which would enable us to say that after that time there was no fear that any mishap would take place.

Combining these statistics of British surgeons with my own, we have 580 limbs operated on by others by the supra. condyloid method, and 804 operated on by myself, which gives 1381 limbs that have been operated on by British surgeons by this method. Of these, ten have died after, though not all from, the operation. There are only three that are stated to ba due to the operation. In one of these cases, however, the operation though credited as Macewen's was not such; so that two only are left: in one the death is clearly due to the operation (septicæmia); while in the other there is a reasonable probability of the operation having been, indirectly at least, the cause of death, the opera. tion having been performed in this instance unuer bad sanitary conditions.

I have observed in the medical journals within the last few months that there have been some cases in which hæmorrhage has followed the supra-condyloid method; one in which the anastomotica magna, and another in which the popliteal had to be ligatured. One surgeon says that he performed the operation in the usual place for Macewen's oporation. He then states that he took his bearings "from the patella." The patella is not given by me as a guide to the place of incision, either in the soft parts or in the bone. It is not a fixed point, and does not bear a constant relation to the plane of the condyles in the deformed condition of the femur. It is probable that if such a guide was taken it might have led some to cut the anastomotica magna or the superior articalar. With regard to the division of the popliteal if the instructions given for the performance of the operation be attended to, it is difficult to understand how it can be divided, except by pure accident. It is, however, possible that it could be divided in one of the following ways. First, by the use of instruments which have a greater breadth than the diameter of the bone. A portion of the instrument might thereby project on the posterior border beyond the bone, and come in contact with the artery. Secondly by not cutting the bone in a methodical manner, and especially by not attending to the directions given to cut the posterior and inner portion of the bone from behind forwards and outwards. If, instead of this, the osteotome be directed from within outwards and backwards, the popliteal might be divided. Thirdly, by holding the osteotome between the finger and thumb, and more especially when this is done at the head of the instrument alone, while the rest of the handle is left unsupported; the chisel is then apt to slip off the bone, and the impulse which it has already received might cause it to penetrate the artery. This is all the more likely to follow if the surgeon holds the osteotome so as to cut away from, instead of to, himself. Recarding suppuration, it seems to me that the chief point in bijnging it about 
is the exercise of force, either during the operation, or afterwards by tight bandaging. There is another way in which it might happen-viz, hy the elastic rod which is sometimes used for arresting the flow of blood in the limb during the operation. This rod may be applied too tightly or too roughly, and so predispose to suppuration.

The placing of the limb correctly on the splints is a point to be attended to in connexion with obtaining perfect results. In any case where it is feared that suppuration might ensue, it would be an element of safety to enlarge the wound to a couple of inches and insert a drainage-tube. In fact, Mr. Lister in performing this operation always does so.

The work of continental surgeons has not been referred to, not that they have been idle-quite the contrary; but the data have not yet been furnished which would enable me to speak with sufficient contidence as to their work. Papers have appeared from the following (among others)-Paul Bruns of Tübingen, Boeckel of Strasburg, Checcarelli Alessandro, Panzeri, Margary, Romano, Morelli, Albertini, Ambrosio, Topai of Italy; and in America we have among others Fowler, Pilcher, and Hutchinson of New York.

\section{OBSERVATIONS ON THE \\ RELATION OF THE PRINCIPAL FISSURES AND CONVOLUTIONS OF THE CEREBRUM TO THE OUTER SURFACE OF THE SCALP.}

By ROBERT W. REID, M.D., F.R.C.S., LECTURER ON ANATOMY, MEDICAL SCHOOL OF ST. THOMAS'S HOSPITAL.

A GOOD deal has been written about the relation of the sulci and convolutions of the cerebrum to the outer surface of the bony cranium, especially with regard to the various sutures. Frequently these sutures are not to be felt through the scalp, and practically, therefore, such relations are of little value to anyone examining the head from a medical or surgical point of view. Hence it occurred to me that a gap might be filled up in regional anatomy by describing the relation of the principal sulci to the outer surface of the scalp, and consequently I made a series of investigations on the dead body, to try if possible to make out some guides by which, on examining a person's head, one might readily be able to localise the chief sulci, and thereby the position of the principal convolutions. Of course it is impossible to draw a line on the scalp exactly to follow a sulcus of the brain, for the simple reason that the sulci are never in any two brains precisely alike, or the shape of the head exactly the same in all cases. We must also remember that, as the surface area of the outside of the scalp is greater than the surface area of the corresponding part of the cerebrum, any lines drawn on the scalp to represent the sulci will be longer than the sulci themselves, and the spaces between those lines, indicating the convolutions, will be larger than the convolutions themselves.

What I propose to do is to show that by taking large and easily felt landmarks on the head, and drawing from these certain lines, those lines will indicate accurately enough for all practical purposes the position of the principal sulci, and that by removing in any of these lines a piece of the scalp and skull an inch square, or by applying the one inch trephine to the skull, with the centre pin on the line, we can expose the fissure in any part of its course.

The landmarks which can easily be felt on the outside of the scalp, and with reference to which lines can be drawn to indicate the position of the sulci are the glabella, or depres. sion between the two nasal eminences just above the root of the nose, external occipital protuberance, superior curved line of the occipital bone, parietal eminence, posterior border of the mastoid process, depression just in front of the external auditory meatus, external angular process of the frontal bone, frontal part of temporal ridge, and the supraorbital notch. If the last is not to be felt, its position will be at the junction of the inner with the middle thirds of the supraorbital margin. We shall also suppose that the base line (Fig. 1), from which all perpendicular lines are drawn runs through the lowest part of the infraorbital margin and the middle of the external auditr.ry meatus.

Longitudinal fissure of cerebrum.-This of course is readily indicated by a line running along the middle line of the top of the head from the glabella to the external occipital protruberance.

Transverse fissure. - This is indicated by drawing a line along the superior curved line of the occipital bone from the external occipital protuberance to the external auditory meatus - that is, along the line of junction of the head with the neck posteriorly.

Fissure of Sylvius. - To find this draw a line from a point one inch and a quarter behind the external angular process of the frontal bone to a point three-quarters of an inch below the most prominent part of the parietal eminence. Measur. ing from before backwards, the first three-quarters of an inch of the line will represent the main fissure, and the rest of the line will indicate the horizontal limb. The ascending limb will start from the posterior end of the line indicating the main fissure-that is, two inches behind and slightly above the external angular process, - and run vertically up. wards for about an inch. (See Fig. 1.)

FIG. 1.

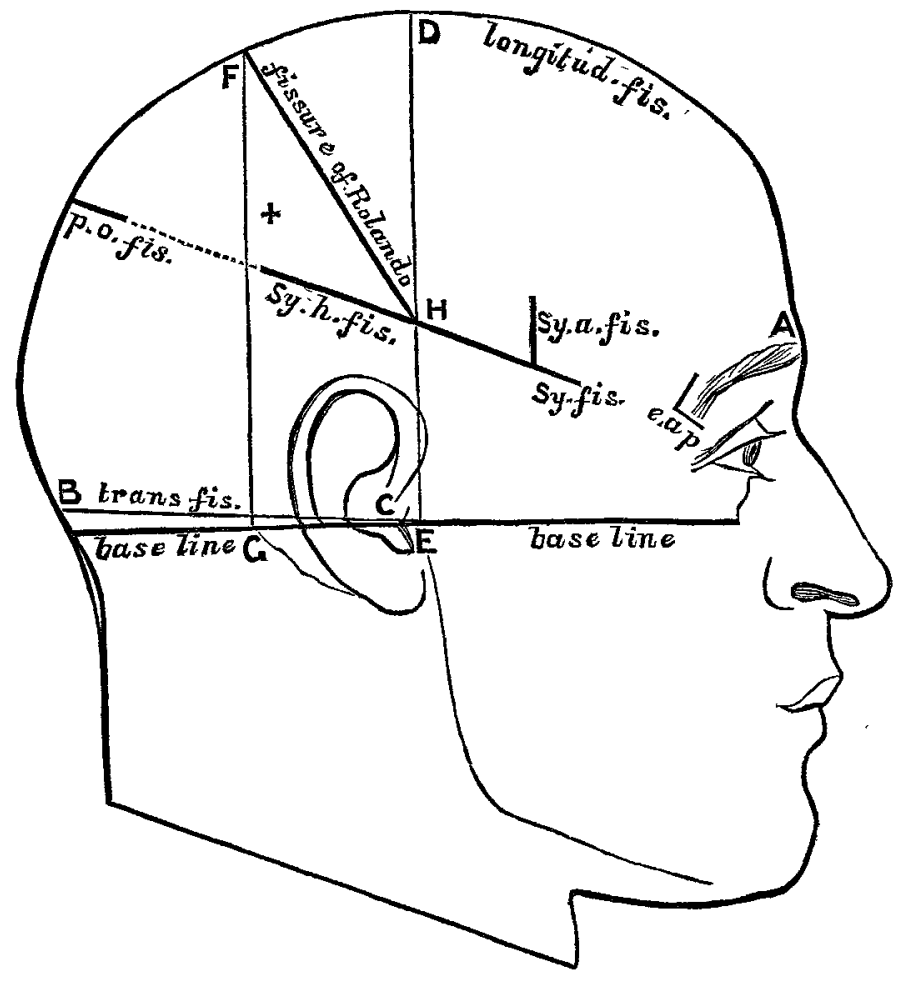

A, Glabella. B, External occipital protuberance. e.a. p., External angular process of frontal. B C, Transverse fissure. A B, Longitudinal fissure. $S y$. fis., Sylvian fissure. Sy. h. fis., Horizontal limb of fissure of Sylvius. Sy. a.fis., Ascending limb of fissure of Sylvius. D E, Perpendicular ine from depression in front of external auditory meatus to midale ling of to of head. F G, Perpendicular line rom posterior end of bas of mastoid process to midale line of top of head. $\mathrm{F} \mathrm{H}$, Fissure of Rolando. p. o. fis., Parieto-occipital fissure. + Most prominent part of
parietal eminence.

Fissure of Rolando.-To find this and, at the same time, the region of the ascending frontal and parietal convolutions, first indicate on the surtace of the scalp the longitudinal fissure and the horizontal limb of the fissure of Sylvius, next, from the base line draw two perpendicular lines to the top of the cranium, one (D E, Fig. 1) from the depression in front of the external and auditory meatus, and another (F G, Fig. 1) from the posterior border of the mastoid process at its root. We shall thus have described on the surface of the head a four-sided figure, bounded above and below by the lines for the longitudinal fissure and horizontal limb of the fissure of Sylvius respectively, and in front and behind by the two perpendicular lines. If we now draw a diagonal line (F H, Fig. l) from the posterior superior angle to the anterior inferior angle of the space, this diagonal line will lie over the fissure of Rolando. In the majority of cases the fissure of Rolando does not actually run into the fissure of Sylvius, a convolution briduing across at that point; hence the lowest half-inch or so of the line would cross this convolution. In those cases where the two fissures join the fissure of Rolando would be indicated by the whole length of the line.

External parieto-occipital fissure.-This fissure is more variable in its position than any of the other principal fissures of the cerebrum, and consequently any indication of it on the 